\title{
Escala de autoeficacia en la vida académica: Propiedades psicométricas en estudiantes de nuevo ingreso al nivel universitario
}

\author{
The Self-Efficacy Scale in Academic Life: Psychometric Properties in New Students to the \\ University Level
}

\section{Escala de Autoeficácia na vida acadêmica: Propriedades psicométricas em novos estudantes que ingressam na graduação}

Rosa María García-Méndez

Universidad Latina

México

rmgarcia@unila.edu.mx

(iD) https://orcid.org/0000-0001-9108-6388

Armando Rivera-Ledesma

Universidad Latina

México

armandoriveral@gmail.com

(iD) https://orcid.org/0000-0003-0273-5273

Recibido • Received • Recebido: 23 / 05 / 2019
Corregido • Revised • Revisado: 16 / 11 / 2020
Aceptado • Accepted • Aprovado: 16 / 02 / 2021

Resumen: El objetivo del presente artículo de investigación fue el desarrollar un instrumento para la medición de la autoeficacia en vida académica (AVA), definida como el conjunto de aspectos psicológicos, sociales, económicos y académicos que directa o indirectamente están asociados a la vida académica del estudiantado. Con un diseño no experimental, descriptivo correlacional, y en una muestra de 2926 estudiantes de nuevo ingreso a educación universitaria, de ambos sexos (55,1\% mujeres), se exploraron las cualidades psicométricas de un conjunto de indicadores de AVA, recolectados mediante un cuestionario implementado en un formulario de Google para su aplicación vía ordenador, obteniéndose un instrumento compuesto de 102 ítems distribuidos en 14 factores que explicaron en total el 59,5\% de la varianza con una confiabilidad Alfa entre .77 y .90 para los factores, y .89 para toda la estructura. La escala obtuvo una validez concurrente adecuada con respecto a la Escala de autoeficacia en conductas académicas al obtener correlaciones favorables entre .40 y .60, en su mayoría. La Escala de autoeficacia en vida académica (EAVA) resultante cuenta además con valores percentiles en cada una de sus sub-escalas y puntos de corte con alta confiabilidad fijados en el percentil 25, que permiten identificar sujetos en riesgo; bajos niveles de autoeficacia se han reportado asociados a deserción escolar y bajo rendimiento académico. Enfocado como instrumento de apoyo diagnóstico a la acción tutorial universitaria, la EAVA se postula como una herramienta útil para la prevención de problemas adaptativos en el estudiantado novel de nivel universitario.

Palabras claves: Autoeficacia académica; escala; rendimiento académico; vida académica. 
http://doi.org/10.15359/ree.25-2.1

http://www.una.ac.cr/educare

educare@una.ac.cr

\begin{abstract}
This research article aimed to develop an instrument for measuring self-efficacy in academic life (SAL) of students, defined as the set of psychological, social, economic, and academic aspects directly or indirectly associated with the students' academic life. Under a non-experimental, descriptive, correlational design, and with a sample of 2926 new students (55.1\% women) to university education, the psychometric qualities of a set of SAL indicators were explored. The information was collected using a questionnaire form implemented via computer. This instrument comprised 102 items distributed in 14 factors that explained $59.5 \%$ of the variance with alpha reliability between .77 and .90 for the factors and .89 for the whole structure. The scale obtained an adequate concurrent validity with respect to the Self-efficacy scale in academic conduct when reaching favorable correlations between .40 and .60. The self-efficacy scale in academic life (SSAL) results also has percentile values in each of its subscales and cut-off values with high reliability set at the 25th percentile, which allows identifying subjects at risk. Low levels of self-efficacy have been reported associated with school dropouts and low academic performance. Focused as a diagnostic support instrument for university tutoring, the SSAL can help prevent adaptive problems in new students at the university level.
\end{abstract}

Keywords: Academic life; academic performance; academic self-efficacy; scale.

Resumo: O objetivo do presente artigo de investigação foi desenvolver um instrumento para a medição da Autoeficácia na Vida Acadêmica (AVA), definido como o conjunto de aspectos psicológicos, sociais, econômicos e acadêmicos que estão direta ou indiretamente associados com a vida acadêmica de estudantes. Com um desenho experimental, descritivo correlacional, e em uma amostra de 2926 novos estudantes ingressantes na educação universitária, de ambos os sexos ( $55.1 \%$ mulheres), foram exploradas as qualidades psicométricas de um conjunto de indicadores AVA, recolhidos por meio de um questionário implementado em um Formulário Google para sua aplicação via computador, obtendo-se um instrumento composto de 102 itens distribuídos em 14 fatores que explicaram no total de $59,5 \%$ da variância, com uma confiabilidade Alfa entre .77 e .90 para os fatores, e .89 para toda a estrutura. O resultado da Escala de Autoeficácia na Vida Acadêmica (EAVA) conta com valores percentis em cada uma da suas subescalas e pontos de corte com alta confiabilidade fixado no percentil 25, permitindo identificar sujeitos de risco; os baixos níveis de autoeficácia foram encontrados associados à deserção escolar e baixo rendimento acadêmico. Focado como um instrumento de apoio diagnóstico para a ação tutorial universitária, a EAVA é reconhecida como uma ferramenta útil para a prevenção de problemas adaptativos em novos estudantes de nível universitário.

Palavras-chave: Autoeficácia acadêmica; desempenho acadêmico; escala; evasão escolar; vida acadêmica.

\title{
Introducción
}

El constructo de Autoeficacia desarrollado por Bandura ha sido ampliamente fructífero al permitir explicar el éxito o fracaso adaptativo de las personas a partir de creencias y sentimientos autorreferentes; se trata de un proceso de orden metacognitivo que Bandura (1977) ha definido como una expectativa de eficacia caracterizada por la convicción de que cada persona misma 
es capaz de llevar a cabo una conducta con el objetivo de producir determinados resultados; la autoeficacia para Bandura es un predictor eficiente tanto de la conducta como de las reacciones afectivas de una persona ante una actividad determinada. En acuerdo con Bandura (1982), las creencias que una persona mantiene sobre sí misma suelen guardar una estrecha relación con respecto a la motivación, el mundo afectivo, determinantes fisiológicos, y factores medioambientales. Ello permite considerar el constructo de autoeficacia como resultado de un proceso integrado por componentes biopsicosociales.

Es aceptado que la autoeficacia puede ser conceptualizada desde una perspectiva general como"un constructo global que hace referencia a la creencia estable de la gente sobre su capacidad para manejar adecuadamente una amplia gama de estresores de la vida cotidiana" (Sanjuán Suárez et al., 2000, p. 509), y desde una perspectiva específica, como un conjunto de creencias asociadas a un campo o ámbito de acción (Tejada Zabaleta, 2005). Uno de estos ámbitos es el académico, cuya importancia ha destacado en los últimos años. La percepción de autoeficacia académica se refiere a la opinión de una persona acerca de su propia capacidad para afrontar y dominar las condiciones cambiantes de su entorno educativo; esta percepción puede afectar sus actividades escolares, sus aspiraciones, el nivel de interés en actividades intelectuales, logros académicos y qué tan bien se preparan para diferentes carreras ocupacionales (Bandura, 1995); ha sido reconocida como una variable mediadora entre las habilidades e historia de logros de una persona, y sus logros subsiguientes. La autoeficacia académica es un buen predictor del rendimiento académico, se ha reportado (González Cabanach et al., 2012) una importante relación directa y significativa entre ella y el bienestar subjetivo (autoaceptación, dominio del entorno).

Una visión predominante de la autoeficacia académica se ha centrado en la mayoría de los casos en aspectos directamente ligados al aprendizaje (v.gr. procesos cognitivos, de lenguaje, comunicación con docentes, investigación, etc.). Sin embargo, estos aspectos parecen estar vinculados, de manera estrecha, con un conjunto de factores de orden psicológico, social, cultural, cuyas características son determinadas por la etapa de desarrollo del sujeto (v.gr. infancia, pubertad y adolescencia, adultez joven, vejez), el contexto social y cultural, su propio proceso de maduración biológica, el nivel educativo en el que se encuentra, etc. Es sabido y aceptado que cada etapa de la existencia individual presenta variaciones que evidencian exigencias adaptativas de transiciones importantes del desarrollo y que confrontan al sujeto con nuevos retos de vida (Babío Galán, 2011; Bereziartua et al., 2017; Borzone Valdebenito, 2017; Martínez Licona et al., 2005) que caracterizan la vida académica.

Evidentemente, estos elementos no actúan de manera aislada; sabemos que el funcionamiento humano es sistémico; un cambio en uno de sus elementos afecta a las demás personas en mayor o menor medida, y condiciona el éxito o fracaso académico, la deserción o permanencia en el sistema educativo, el rendimiento académico, y otros importantes aspectos. El alumnado afronta un sistema cultural, un conjunto nuevo de factores para el que va a 
http://doi.org/10.15359/ree.25-2.1

http://www.una.ac.cr/educare

educare@una.ac.cr

percibirse más o menos eficaz. Es importante hablar desde un enfoque integral de autoeficacia en vida académica, en virtud del conjunto de factores psicológicos, sociales, económicos y académicos que, directa o indirectamente, influyen la vida académica del estudiantado. La vida académica universitaria puede ser comprendida como todo lo que hace y vive el estudiantado al relacionarse entre sí, con docentes, y en general, con todas las personas que de una manera o de otra participan en su formación universitaria; es todo lo que hace cuando estudia, cuando realiza prácticas, cuando hace sus tareas, cuando investiga; son todas las actividades, materias, compromisos, obligaciones, etc., en que participa, ya sea que esté dentro de la institución universitaria, en instalaciones educativas de otras instituciones o, incluso, en casa, ya sea de forma presencial o virtual.

Borzone Valdebenito (2017) ha destacado que la adaptación a la vida universitaria no es un proceso sencillo, es muy común que el abandono escolar ocurra con frecuencia durante los primeros tres semestres de la carrera profesional en estudio a partir del concurso de una variedad de factores, como han señalado otros investigadores (Abello et al., 2012; Londoño, 2009, citados por Borzone Valdebenito, 2017). Siguiendo a la investigadora, el proceso de adaptación a la vida universitaria involucrará aspectos ligados a tres dimensiones: dimensión personal, dimensión interpersonal y dimensión contextual. De manera complementaria, en este proceso adaptativo ocurrirán Vivencias académicas que la autora, en acuerdo con Almeida, et al. (1999, citado por Borzone Valdebenito, 2017), define como "opiniones, y sentimientos que el estudiante tiene respecto a experiencias cotidianas en el contexto de la enseñanza superior" (p. 269), compuestas de las siguientes variables: dificultades personales, relaciones interpersonales, valoración de la carrera, estrategias de estudio y valoración de la institución.

Es posible reconocer que las actividades académicas se desarrollan en un ámbito compuesto de distintos factores interrelacionados con los que el estudiantado debe lidiar a fin de adaptarse eficientemente. Las actividades académicas se desarrollan en un medio inmediato (v.gr. escuela, colegio, universidad), caracterizado por la presencia de un marco normativo, metas sociales asociadas a la eficiencia académica esperada, una cultura que limita o expande el orden social, norma las relaciones económicas, religiosas, promueve tradiciones, ideales de vida, etc., que condicionan la adaptación de la persona, e influyen sus expectativas. Todos estos elementos conforman la vida académica; un periodo de la vida al que el estudiantado necesita adaptarse; un microcosmos que representa los intereses, valores y objetivos de la sociedad a la que el propio estudiantado pertenece o desea pertenecer.

Si se mantiene una visión sistémica de la autoeficacia académica, habría que pensar en un ámbito ampliado que toma relevancia para el ejercicio de la tutoría, pero no solo para la acción tutorial, sino para la estabilidad institucional donde es valorada. Tendríamos autorización para hablar de autoeficacia en la vida académica, definiéndola como las creencias y juicios con respecto a la propia capacidad para responder, eficientemente, a las demandas 
http://doi.org/10.15359/ree.25-2.1

del medio académico real o virtual, en el que se cursa un determinado programa de estudios. El medio académico no se ciñe a las paredes del centro educativo; la vinculación universitaria, las relaciones académicas extramuros, el contexto productivo, la familia, etc., son todos ellos factores capaces de influir la vida académica.

En ese contexto de ideas, la acción tutorial ha sido reconocida como una importante herramienta formativa para el quehacer educativo de las universidades (de la Cruz Flores et al., 2011); esta se ha ido institucionalizando (Álvarez y Pons, 2013), y hoy por hoy, la consideración e implantación de una acción tutorial de calidad universitaria en la cual se acentúe una formación integral del alumnado, toma cada vez mayor relevancia, habiéndose aportado evidencia sobre su importancia para el logro de la excelencia académica (López Martín et al., 2014). En México, se ha sugerido la implementación de acciones tutoriales basadas en problemáticas específicas e inherentes a cada institución educativa (ANUIES, 2000, citado por Martínez Licona et al., 2005), lo cual es un reconocimiento a la singularidad cultural del contexto educativo del estudiantado, por un lado, de la institución por otro, y de la interrelación existente entre ambos. En esa tesitura, el diagnóstico de la autoeficacia en la vida académica toma una relevancia fundamental.

La acción tutorial efectiva parte del diagnóstico de problemáticas específicas existentes; se ha destacado la necesidad de contar con instrumentos válidos y confiables sobre los procesos de tutoría (de la Cruz Flores et al., 2011); entre estos procesos, el diagnóstico de la autoeficacia de la vida académica es especialmente relevante porque proporcionaría, en el caso de los instrumentos de medición, áreas en déficit específicas basadas en fuentes empíricas hacia las cuales dirigir los esfuerzos de tutoría.

El diagnóstico de la autoeficacia del alumnado constituye una aproximación a sus creencias acerca de su propia capacidad para lograr una adaptación eficiente al mundo académico hoy, y profesional, mañana; un acercamiento a su mundo afectivo. Existe evidencia reportada sobre la asociación entre rasgos psicopatológicos, distrés o malestar psicológico, personalidad y autoeficacia (Caprara et al., 2010; Caprara et al., 2011; Fosse et al., 2015; Gómez et al., 2007; Tahmassian y Jalali-Moghadam, 2011), que ha destacado el papel mediador de la autoeficacia entre los rasgos de personalidad y el comportamiento; las creencias de autoeficacia permiten que los rasgos de personalidad se expresen como un comportamiento regulado en la interacción con el medio ambiente; la autoeficacia conlleva pensamientos, motivaciones, sentimientos y comportamientos (Tahmassian y Jalali-Moghadam, 2011), manteniendo una asociación inversa y significativa con los rasgos psicopatológicos de personalidad y el malestar psicológico (v.gr. somatización, obsesión-compulsión, sensibilidad interpersonal, depresión, ansiedad, hostilidad, fobias, pensamiento paranoide, y psicoticismo (Alina Karouei et al., 2008; Burris et al., 2009; Muris, 2002); a mayores niveles de autoeficacia, menores niveles de distrés psicológico y menores grados de psicopatología; a menores niveles de autoeficacia, mayor malestar psicológico y mayores grados de psicopatología. 
http://doi.org/10.15359/ree.25-2.1

http://www.una.ac.cr/educare

educare@una.ac.cr

Se ha destacado que evaluar la autoeficacia permite la identificación de estudiantes en riesgo académico (Alina Karouei et al., 2008; Gore, 2006; Davidson et al., 2012; Mercer et al., 2011, citados por Dominguez-Lara, 2016), para la consecución de estrategias de intervención tutorial dirigidas a la prevención de problemas adaptativos relacionados con la vida académica, entre los que se han identificado la incidencia de ansiedad significativa ante los exámenes, agotamiento emocional, bajas aspiraciones académicas (Domínguez-Lara, 2016), deserción escolar y otros. La autoeficacia académica ha sido investigada con respecto a la carrera elegida, la labor docente, la motivación y el rendimiento académico del estudiantado (Kohler Herrera, 2009) y, consecuentemente, se han desarrollado instrumentos de medición apropiados centrados en tres temáticas: 1. Autoeficacia generalizada, considerando el área académica. 2. Centrados en lo académico. 3. Centrados en la autoeficacia académica de una forma más específica (Barraza Macías, 2010). La presente investigación se centró en el desarrollo de una escala válida y confiable con valores normativos, que permitiese evaluar la autoeficacia en la vida académica de estudiantes de nuevo ingreso al nivel superior, como una herramienta susceptible de ser empleada como paso previo al diseño de acción tutorial.

\section{Método}

La presente investigación se basó un diseño transversal, descriptivo-correlacional.

\section{Muestras}

Las muestras fueron elegidas por disponibilidad en acuerdo con los siguientes criterios de inclusión:

1. Para la primera etapa del proyecto el criterio de selección de sujetos fue que estuviesen cursando el primero o segundo semestre de licenciatura al momento de participar en la encuesta. Para la segunda etapa, el criterio demandó que los sujetos fuesen de nuevo ingreso a la universidad (no más allá del primer mes del semestre). 2. De ambos sexos. 3. Pertenecientes a cualquiera de las carreras en operación. 3. Que aceptaran participar en la investigación de manera voluntaria e informada. Único criterio de exclusión: estudiantes con signos o síntomas de enfermedad o cualquier otra causa que alterase su correcto desempeño durante la encuesta.

El proceso de elaboración de la EAVA se compuso de dos etapas:

1. Determinación de reactivos y estudio piloto. En esta etapa se consideró una muestra total de 693 estudiantes provenientes de dos submuestras elegidas por disponibilidad. La muestra 1a, de 254 sujetos de la Ciudad de México y la muestra 1b, empleada para el estudio piloto del instrumento compuesta de 439 sujetos del Estado de Morelos. La Tabla 1 describe sus características sociodemográficas. 
http://doi.org/10.15359/ree.25-2.1

2. Evaluación psicométrica de la escala. La muestra se compuso de un total de 2926 sujetos pertenecientes a distintos ciclos escolares de dos campus ubicados en la Ciudad de México y dos en el Estado de Morelos, entre los años 2017 y 2019. Sus características sociodemográficas se presentan en la Tabla 1.

Tabla 1: Información sociodemográfica de las muestras

\begin{tabular}{|c|c|c|c|c|c|c|}
\hline \multirow[b]{2}{*}{ Sexo } & \multicolumn{2}{|c|}{ Muestra 1a } & \multicolumn{2}{|c|}{ Muestra $1 \mathrm{~b}$} & \multicolumn{2}{|c|}{$2^{\text {a }}$ Muestra } \\
\hline & $f$ & $\%$ & $f$ & $\%$ & $f$ & $\%$ \\
\hline Mujeres & 148 & 58.3 & 262 & 59.7 & 1613 & 55.1 \\
\hline Hombres & 106 & 41,7 & 177 & 40,3 & 1313 & 44.9 \\
\hline Edad & M & DS & M & DS & M & DS \\
\hline Mujeres & 21.7 & 2.1 & 21.4 & 3.2 & 20.9 & 4.7 \\
\hline Hombres & 22.0 & 2.0 & 21.8 & 2.9 & 20.9 & 4.0 \\
\hline Carrera & $\mathrm{F}$ & $\%$ & $\mathrm{~F}$ & $\%$ & $\mathrm{~F}$ & $\%$ \\
\hline Administración & 71 & 27.9 & 72 & 16.4 & 545 & 18.6 \\
\hline Comunicación & 69 & 27.1 & 75 & 17.0 & 385 & 13.2 \\
\hline Contaduría & 29 & 11.4 & 32 & 7.4 & 220 & 7.5 \\
\hline Derecho & 85 & 33.6 & 99 & 22.5 & 622 & 21.3 \\
\hline Gastronomía & & & 22 & 5.1 & 180 & 6.2 \\
\hline Informática & & & 11 & 2.5 & 83 & 2.8 \\
\hline Mercadotecnia & & & 27 & 6.2 & 336 & 11.5 \\
\hline Pedagogía & & & 26 & 5,9 & 162 & 5.5 \\
\hline Psicología & & & 70 & 15.9 & 353 & 12.1 \\
\hline Turismo & & & 5 & 1.1 & 40 & 1.4 \\
\hline Total & 254 & 100 & 439 & 100 & 2926 & 100 \\
\hline \multicolumn{7}{|l|}{ Entidad federativa } \\
\hline Ciudad de México & 254 & 100 & & & 2000 & 68.4 \\
\hline Estado de Morelos & & & 439 & 100 & 926 & 31.6 \\
\hline Total & 254 & 100 & 439 & 100 & 2926 & 100 \\
\hline
\end{tabular}

Nota: Datos propios. 
http://doi.org/10.15359/ree.25-2.1

http://www.una.ac.cr/educare

educare@una.ac.cr

Instrumentos empleados. Además de información sociodemográfica básica, se utilizaron dos instrumentos de medición:

Cuestionario de frases incompletas (CFI). A fin de conocer aquellos aspectos de la vida académica que resultaban importantes al momento dela encuesta para las personas entrevistadas, desde una perspectiva cualitativa se diseñó un cuestionario con ocho frases incompletas estímulo; cuatro iguales en sentido positivo (Me siento muy capaz de ...), y cuatro iguales en sentido negativo (Me siento poco capaz de .... Esta técnica de investigación originalmente está basada en el mecanismo de proyección psíquica propuesto por la teoría psicoanalítica e introducida en tests ampliamente conocidos como el Test de frases incompletas de Sacks, el Test de apercepción temática, el Test del dibujo de la figura humana, entre otros. Está técnica estimula la generación de respuestas, relacionadas con temas específicos determinados por un estímulo ambiguo dispuesto por el investigador (Sabogal, 2004); las respuestas así obtenidas pueden estar asociadas a creencias y temores personales, valores, etc., y constituyen así un medio importante de acceso a los intereses, conflictos y contradicciones, necesidades, actitudes y motivos del sujeto; Frankl (1939, citado por Sabogal, 2004) señaló que la interpretación de los estímulos externos se ve influida por "[las] necesidades, intereses y organización psicológica" (p. 135), de las personas; las percepciones así obtenidas suelen ser ricas en contenido, y genuinas, por no estar influidas por el investigador (Sabogal, 2004). Esta técnica es flexible y aplicable en el campo educativo (Maglio et al., 2010; Sneiderman, 2006). Así, en esta etapa de la investigación, el CFI se empleó como recurso de evocación de respuestas como paso previo de orden cualitativo a un proceso de construcción psicométrica. Los métodos proyectivos, permiten investigar la subjetividad de las personas y de ahí pasar a la "operacionalización de ciertos constructos teóricos que, de otra manera, serían intangibles" (Sneiderman, 2006, p. 299). En la sección Procedimiento se describen los resultados de esta aplicación, concerniente a la obtención de descriptores como paso previo a la determinación de factores (constructos) asociados a la autoeficacia en la vida académica.

2. Escala de autoeficacia en conductas académicas (EACA) de Blanco Vega et al. (2011). Fue evaluada en estudiantado universitario mexicano de nuevo ingreso en la Universidad Autónoma de Chihuahua. La escala consta de 13 ítems distribuidos en tres factores: Excelencia, comunicación y atención con un formato de respuesta ordinal de 10 puntos; la EACA es un instrumento robusto y con buenas propiedades psicométricas diseñado para evaluar autoeficacia en conductas académicas en tres escenarios: Escenario actual, Escenario ideal y Escenario de cambio; en esta investigación solo se tomó el primero de ellos, obteniéndose una confiabilidad alfa de .85 , .85 y .90 para sus factores excelencia, comunicación y atención, respectivamente, y de .92 para el total de la escala. El factor excelencia se refiere al cumplimiento en tareas, la preparación para exámenes, entrega puntual de trabajos encargados, cumplimiento de asistencia a clases y puntualidad. El factor comunicación alude a la expresión clara de las ideas, la emisión de comentarios y aportaciones pertinentes, el dialogar desacuerdos con docentes y el sentirse bien con la propia exposición frente a la clase o un grupo numeroso de personas.

8

Rosa María García-Méndez y Armando Rivera-Ledesma

Los artículos de la Revista Electrónica Educare del Centro de Investigación y Docencia en Educación de la Universidad Nacional, Costa Rica, se comparten bajo términos de la Licencia Creative Commons: Reconocimiento, No Comercial, Sin 0bra Derivada 3.0 Costa Rica. Las autorizaciones adicionales a las aquí delimitadas se pueden obtener en el correo: educare@una.cr 
http://doi.org/10.15359/ree.25-2.1

El factor atención repara en escuchar atentamente al profesorado cuando imparte clase, aclara dudas a compañeros o compañeras, o pregunta o comenta al grupo en sus preguntas y aportaciones (Blanco Vega et al. 2011).

\section{Procedimiento}

Para la primera fase del proyecto, y con el objetivo de reunir descriptores para la elaboración de un cuestionario de ítems adecuados para constituir la EAVA, se aplicó el CFI; como resultado se obtuvieron 1379 frases provenientes de 254 estudiantes, algunas de las cuales fueron eliminadas por su valor espurio, mala redacción, por ser confusas o estar repetidas, eligiéndose solo las frases cuya redacción era clara, no ambigua y directamente ligada a la vida académica. Para la determinación de estos aspectos se implementó un proceso de triangulación a cargo de tres psicólogos familiarizados con el tema, cuyo consenso alcanzó un remanente total de 152 frases elegidas por unanimidad con base en los criterios descritos de claridad y pertinencia. Con estas frases se estructuró un cuestionario que finalmente constituyó el Cuestionario de la vida académica (CVA). Este CVA fue presentado a un grupo de estudiantes de manera individual hasta verificar que todos los indicadores fuesen adecuadamente comprendidos, a juicio de tres profesionales de psicología a cargo de esta función.

A continuación, se llevó a cabo un estudio piloto con el CVA dispuesto con un formato de respuesta tipo Likert de cuatro puntos (Ver apéndice A) (1. Nunca o casi nunca; 2. Algunas veces; 3. Frecuentemente y 4. Siempre o Casi siempre), fue incorporado a la aplicación Formularios de Google junto con información sociodemográfica y la escala EACA. El formulario resultante fue aplicado al estudiantado mediante ordenadores dispuestos en el centro de cómputo del campus elegido para esta etapa de la investigación. Los resultados arrojaron una estructura multifactorial conceptualmente definida, con una confiabilidad alfa de Cronbach compuesta por valores entre .68 y .88 para los factores, y de .85 para la escala general. La validez concurrente contra la EACA reportó correlaciones entre .42 y .65. Con estos resultados iniciales finalizó la primera etapa.

En la segunda etapa, se decidió el empleo de una muestra suficientemente amplia para la evaluación del CVA, estimando 20 sujetos por reactivo; es decir, 3000 sujetos en total que serían encuestados con el formulario citado a partir del año 2017 y hasta principios del 2019 (Ver apéndice A). Las muestras sucesivas están compuestas del estudiantado de nuevo ingreso de los cuatro campus de la universidad. Así, se reunieron 2926 cuestionarios satisfactoriamente resueltos. Las instrucciones fueron: A continuación, encontrarás una serie de afirmaciones que completan la pregunta: ¿Con qué frecuencia te sientes capaz de ...? Responde cada una utilizando las opciones de respuesta que aparecen en el margen derecho. Recuerda que todas tus respuestas son consideradas confidenciales.

Los datos así obtenidos fueron analizados en el programa IBM SPSS Statistics v.25, eliminándose de la base de datos inicial aquellos registros extremos o atípicos; no hubo datos ausentes o perdidos, en virtud de que el Formulario empleado fue programado para exigir el completo llenado del cuestionario (Tabla 1). 
http://doi.org/10.15359/ree.25-2.1

http://www.una.ac.cr/educare

educare@una.ac.cr

En todas las encuestas, se solicitó a cada estudiante el otorgamiento de su consentimiento informado asegurándose la privacidad de la información, así como la libertad de suspender la aplicación y retirarse en el momento en que lo considerara pertinente.

\section{Resultados}

En principio se exploró la validez estructural de la escala. Se estimó la medida KaiserMeyer-Olkin de adecuación de muestreo y la prueba de esfericidad de Bartlett con resultados de .975 y .000 respectivamente, lo cual apoyó la pertinencia del análisis factorial de los datos.

Así, se practicó un análisis de componentes principales con rotación varimax, y valores eigen mayores a 1, el cual arrojó una estructura final compuesta de 14 factores que en conjunto explicaron el 59,5\% de la varianza (Tabla 2), con un total de 102 ítems con cargas iguales o superiores a .40 (Tabla 3). La confiabilidad de la escala en acuerdo con el método Alfa de Cronbach fue de .77 a .90 para sus factores, y .89 para toda la estructura. Finalmente, cada factor fue nombrado en función del contenido de los ítems que lo conformaban, y a juicio consensuado entre el equipo investigador (Tabla 2). Los ítems que constituyen los factores obtenidos se muestran en el Apéndice A de este documento.

Tabla 2: Estructura factorial de la EAVA

\begin{tabular}{|c|c|c|c|}
\hline Factor & $S^{2} E$ & Alfa & Items y cargas \\
\hline \multicolumn{4}{|l|}{ Logros profesionales } \\
\hline $\begin{array}{l}\text { Ser capaz de alcanzar los logros y metas propuestas en torno a la propia } \\
\text { vida y el desarrollo profesional }\end{array}$ & $29.6 \%$ & .90 & $\begin{array}{l}1,15,29,91,42,99,100,84 \\
93,101,92,102 . \\
\text { Cargas entre } 0.503 \text { y } 0.780 .\end{array}$ \\
\hline \multicolumn{4}{|l|}{ Liderazgo } \\
\hline $\begin{array}{l}\text { Ser capaz de dirigir un grupo de personas, capacitarlas, tomar } \\
\text { decisiones, planear e influir a las demás. }\end{array}$ & $6.3 \%$ & .90 & $\begin{array}{l}2,16,30,75,57,66,43 \\
89,76 . \\
\text { Cargas entre } 0.478 \text { y } 0.712 .\end{array}$ \\
\hline
\end{tabular}

\section{Habilidades de investigación}

Ser capaz de diseñar investigaciones, buscar información, redactar apropiadamente, actuar con meticulosidad y de forma analítica.

$3.6 \% \quad .88 \quad 3,17,31,67,90,77,44,65,81,56,88$. Cargas entre 0.416 y 0.659 .

\section{Responsabilidad académica}

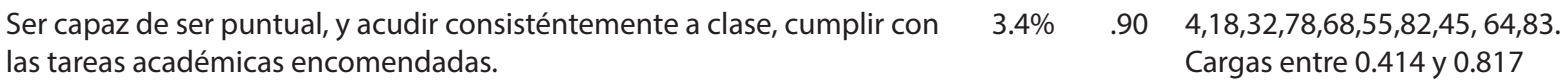


http://doi.org/10.15359/ree.25-2.1

\begin{tabular}{lccc}
\hline \multicolumn{1}{c}{ Factor } & SE & Alfa & \multicolumn{1}{c}{ Items y cargas } \\
\hline Concentración y comprensión académicas & & & \\
$\begin{array}{l}\text { Ser capaz de concentrarse en lecturas, temas, estudiar para exámenes, } \\
\text { comprendiendo el material de lectura y a los(as) autores(as). }\end{array}$ & $2.6 \%$ & .89 & $\begin{array}{l}5,19,33,69,80,46,79,63,54 . \\
\text { Cargas entre } 0.471 \text { y } 0.726\end{array}$ \\
\hline
\end{tabular}

\section{Creatividad e innovación}

Ser capaz de ser creativo(a), innovador(ra), generando buenas ideas e $\quad 2.2 \% \quad .90 \quad 6,20,47,94,41,96,85,97$. improvisando soluciones.

\section{Socialización y compañerismo}

Ser capaz de ser sociable, convivir, interactuar, trabajar, comunicarse con $\quad 1.9 \% \quad$.88 $\quad 7,21,86,58,74,95,40,49,98,59$.

las demás personas, conocidas o no.

\section{Exposición frente a grupo}

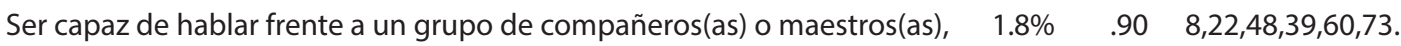
controlando el nerviosismo, exponiendo las propias ideas.

Cargas entre 0.636 y 0.797

\section{Organización académica}

Ser capaz de organizar las propias actividades, el tiempo, con orden. $\quad \begin{aligned} & 1.7 \% \quad .90 \quad 9,23,71,87,50,72 .\end{aligned}$

Cargas entre 0.465 y 0.738

\section{Control de impulsos}

Ser capaz de controlarse cuando se está bajo estrés, controlar la ira, ser $\quad 1.6 \% \quad .80 \quad 10,24,38,61,51,70$. tolerante con los demás, paciente y estable

Planeación académica

Ser capaz de planear actividades académicas, exposiciones en clase, trabajos. $\quad 1.3 \% \quad .84 \quad 11,25,37,52,62$.

Cargas entre 0.480 y 0.601

\section{Aprendizaje fluido}

Ser capaz de aprender rápido y fácilmente.

$1.3 \% \quad .82 \quad 12,26,36$.

Cargas entre 0.558 y 0.639

\section{Trabajo bajo presión}

Ser capaz de trabajar bajo presión, incluso en varias actividades al mismo tiempo.

$1.0 \% \quad .77 \quad 13,27,35$.

Cargas entre 0.450 y 0.834

\section{Asimilación de información}

Ser capaz de aprender nuevos temas durante las actividades en clase, sosteniendo la atención en ella y en los ejemplos que se proporcionan.

$1.1 \% \quad .82 \quad 14,28,34,53$

Cargas entre 0.407 y 0.484

\section{Total EAVA}

$59.5 \% \quad .89$

Nota: Elaboración con datos propios. $\mathbf{S}^{\mathbf{2}} \mathbf{E}=$ Varianza explicada $\quad$ Alfa $=$ Alfa de Cronbach. 
http://doi.org/10.15359/ree.25-2.1

http://www.una.ac.cr/educare

educare@una.ac.cr

Por otro lado, la comparación de factor contra factor de la EAVA arrojó, en general, correlaciones satisfactorias que permitieron evidenciar tanto la independencia de cada dimensión, como su correspondencia en torno a un mismo constructo. Los resultados aportaron correlaciones superiores a .40 y hasta .65 para la mayoría de las comparaciones, lo cual aporta evidencia acerca de su validez y pertinencia en torno al concepto de autoeficacia.

La validez concurrente se realizó mediante la comparación de cada factor contra los tres factores propuestos por la EACA (Tabla 3). Al estimar la relación entre las puntaciones de los totales de la EACA y la EAVA se advierte que, en su mayoría, sus correlaciones son superiores, a .40; si bien ambas escalas parecen enfocarse a la autoeficacia académica, también parece ser que exploran diferentes facetas.

Tabla 3: Correlaciones entre la Escala de autoeficacia en conductas académicas (EACA) y la Escala de autoeficacia en vida académica (EAVA)

\begin{tabular}{|c|c|c|c|c|c|c|c|c|c|c|c|c|c|c|c|}
\hline \multirow[b]{2}{*}{ EACA } & \multicolumn{15}{|c|}{ EAVA } \\
\hline & LP & L & $\mathrm{HI}$ & RA & CA & C & SC & EG & $\mathrm{OA}$ & $\mathrm{Cl}$ & PA & $\mathrm{AF}$ & TP & $\mathrm{Al}$ & ToV \\
\hline C & .38 & .55 & .48 & .33 & .49 & .46 & .42 & .59 & .41 & & .46 & .46 & .37 & .44 & .61 \\
\hline A & .43 & .33 & .46 & .47 & .48 & .36 & .36 & & .46 & .34 & .43 & .36 & & .51 & .54 \\
\hline$E$ & .44 & & .43 & .56 & .43 & .31 & & & .49 & & .43 & .33 & & .47 & .50 \\
\hline ToC & .47 & .46 & .52 & .50 & .54 & .44 & .42 & .47 & .50 & & .51 & .44 & & .53 & .64 \\
\hline \multicolumn{4}{|c|}{$\begin{array}{l}C=\text { Comunicación } \\
A=\text { Atención } \\
E=\text { Excelencia }\end{array}$} & \multicolumn{6}{|c|}{$\begin{array}{l}\mathrm{LP}=\text { Logros profesionales } \\
\mathrm{L}=\text { Liderazgo } \\
\mathrm{HI}=\text { Habilidades de investigación } \\
\mathrm{RA}=\text { Responsabilidad académica } \\
\mathrm{CA}=\text { Concentración comprensión } \\
\mathrm{C}=\text { Creatividad e innovación } \\
\mathrm{SC}=\text { Socialización y compañerismo } \\
\mathrm{EG}=\text { Exposición frente a grupo } \\
\mathrm{OA}=\text { Organización académica }\end{array}$} & \multicolumn{6}{|c|}{$\begin{array}{l}\mathrm{Cl}=\text { Control de impulsos } \\
\mathrm{PA}=\text { Planeación académica } \\
\mathrm{AF}=\text { Aprendizaje fluido } \\
\mathrm{TP}=\text { Trabajo bajo presión } \\
\mathrm{Al}=\text { Asimilación de información } \\
\mathrm{ToV}=\text { Total de EAVA } \\
\mathrm{ToC}=\text { Total de EACA }\end{array}$} \\
\hline
\end{tabular}

Nota: Elaboración con datos propios. Correlaciones significativas con $\mathrm{p}<.01$

Por otro lado, y a fin de contar con información adecuada para el desarrollo de datos normativos para la EAVA, se exploró la existencia de diferencias por sexo. Se detectaron diferencias estadísticamente significativas en prácticamente todos los factores, con excepción de las subescalas de creatividad e innovación, control de impulsos, aprendizaje fluido y trabajo bajo presión. Sin embargo, siguiendo las sugerencias de Morales Vallejo (2012), se estimó la magnitud del efecto, para lo cual se obtuvieron, mediante la $d$ de Cohen, medidas iguales o inferiores a .07, 
http://doi.org/10.15359/ree.25-2.1 http://www.una.ac.cr/educare educare@una.ac.cr

que permiten concluir que esta magnitud del efecto entre sexos era lo suficientemente débil como para no justificar datos normativos para mujeres y hombres. A partir de aquí, y dado que el objetivo de la EAVA debía ser la evaluación de la autoeficacia en la vida académica y servir de guía para la acción tutorial dirigida a su fortalecimiento, se determinaron las puntuaciones naturales en cada factor y sus percentiles correspondientes; se emplearon los percentiles 5, 10, 15, 20, 25 y sus consiguientes múltiplos hasta el 100; se estableció, como punto de corte, el percentil 25. Finalmente, se determinó la confiabilidad de los puntos de corte con las observaciones de Gempp y Saiz (2014), y se confirmaron medidas adecuadas para cada uno (Tabla 4).

Tabla 4: Confiabilidad de los puntos de corte de la EAVA

\begin{tabular}{lccccc}
\hline & Alfa de Cronbach & Media & Varianza & Punto de corte & K2 \\
\hline Logros profesionales & .90 & 43.9 & 21.3 & 42 & .91 \\
Liderazgo & .90 & 26.6 & 33.3 & 23 & .93 \\
Habilidades de investigación & .88 & 32.8 & 31.5 & 29 & .92 \\
Responsabilidad académica & .90 & 35.8 & 19.6 & 33 & .93 \\
Concentración y comprensión & .89 & 27.9 & 23.8 & 25 & .92 \\
Creatividad e innovación & .90 & 26.8 & 19.8 & 24 & .93 \\
Socialización y compañerismo & .88 & 33.0 & 25.4 & 30 & .91 \\
Exposición frente a grupo & .90 & 17.7 & 16.0 & 15 & .93 \\
Organización académica & .90 & 20.0 & 11.9 & 18 & .93 \\
Control de impulsos & .80 & 19.6 & 10.4 & 18 & .84 \\
Planeación académica & .84 & 15.9 & 8.4 & 14 & .89 \\
Asimilación de información & .82 & 13.8 & 4.0 & 12 & .90 \\
Trabajo bajo presión & .77 & 9.5 & 4.3 & 8 & .85 \\
Aprendizaje fluido & .82 & 9.0 & 3.2 & 8 & .86 \\
\hline EAVA Total & .89 & 338.6 & 1547.8 & 311 & .93 \\
\hline
\end{tabular}

Nota: Elaboración con datos propios.

Así, es posible trazar un perfil individual que, de manera gráfica, permita una más sencilla y clara interpretación de los resultados en función del riesgo alto, medio o bajo, según el grupo normativo de 2926 estudiantes de nuevo ingreso en cada una de las 14 áreas de autoeficacia consideradas (Tabla 5). 
http://doi.org/10.15359/ree.25-2.1

http://www.una.ac.cr/educare

educare@una.ac.cr

Tabla 5: Percentiles para la calificación de puntajes naturales de la EAVA

\begin{tabular}{|c|c|c|c|c|c|c|c|c|c|c|c|c|c|c|c|c|}
\hline & & LP & L & $\mathrm{HI}$ & RA & CA & C & SC & EG & OA & $\mathrm{Cl}$ & PA & $\mathrm{AF}$ & TP & Al & ToV \\
\hline Riesgo & Pc & \multicolumn{15}{|c|}{ Puntuaciones naturales } \\
\hline \multirow{5}{*}{ ALTO } & 5 & 35 & 17 & 24 & 28 & 20 & 19 & 24 & 12 & 14 & 14 & 11 & 11 & 6 & 6 & 274 \\
\hline & 10 & 37 & 19 & 25 & 30 & 22 & 21 & 26 & 12 & 15 & 15 & 12 & 12 & 7 & 6 & 288 \\
\hline & 15 & 38 & 20 & 27 & 30 & 23 & 22 & 28 & 13 & 17 & 16 & 13 & 12 & 7 & 7 & 297 \\
\hline & 20 & 40 & 22 & 28 & 31 & 24 & 23 & 29 & 14 & 17 & 17 & 14 & 12 & 8 & 7 & 305 \\
\hline & 25 & 42 & 23 & 29 & 33 & 25 & 24 & 30 & 15 & 18 & 18 & 14 & 12 & 8 & 8 & 311 \\
\hline \multirow{9}{*}{ MEDIO } & 30 & 43 & 24 & 30 & 34 & 25 & 24 & 30 & 15 & 18 & 18 & 15 & 12 & 9 & 8 & 317 \\
\hline & 35 & 44 & 24 & 30 & 35 & 26 & 25 & 31 & 16 & 18 & 18 & 15 & 13 & 9 & 9 & 322 \\
\hline & 40 & 45 & 25 & 31 & 36 & 27 & 25 & 32 & 17 & 19 & 19 & 15 & 13 & 9 & 9 & 328 \\
\hline & 45 & 45 & 26 & 32 & 37 & 27 & 26 & 33 & 17 & 20 & 19 & 15 & 14 & 9 & 9 & 334 \\
\hline & 50 & 46 & 27 & 33 & 37 & 28 & 27 & 33 & 18 & 20 & 20 & 16 & 14 & 10 & 9 & 340 \\
\hline & 55 & 46 & 27 & 33 & 38 & 28 & 28 & 34 & 18 & 21 & 20 & 16 & 14 & 10 & 9 & 345 \\
\hline & 60 & 47 & 28 & 34 & 38 & 29 & 29 & 35 & 19 & 22 & 21 & 17 & 15 & 10 & 9 & 351 \\
\hline & 65 & 47 & 29 & 35 & 39 & 30 & 30 & 36 & 19 & 22 & 21 & 17 & 15 & 11 & 9 & 357 \\
\hline & 70 & 47 & 30 & 36 & 39 & 31 & 30 & 37 & 20 & 23 & 22 & 18 & 15 & 11 & 10 & 363 \\
\hline \multirow{7}{*}{ BAJO } & 75 & 48 & 31 & 37 & 40 & 32 & 31 & 37 & 21 & 23 & 22 & 18 & 16 & 11 & 10 & 369 \\
\hline & 80 & 48 & 32 & 38 & 40 & 33 & 32 & 38 & 22 & 24 & 23 & 19 & 16 & 12 & 11 & 376 \\
\hline & 85 & 48 & 33 & 39 & 40 & 34 & 32 & 39 & 23 & 24 & 23 & 20 & 16 & 12 & 11 & 382 \\
\hline & 90 & 48 & 35 & 41 & 40 & 35 & 32 & 39 & 23 & 24 & 24 & 20 & 16 & 12 & 12 & 391 \\
\hline & 95 & 48 & 36 & 42 & 40 & 36 & 32 & 40 & 24 & 24 & 24 & 20 & 16 & 12 & 12 & 400 \\
\hline & 100 & 48 & 36 & 44 & 40 & 36 & 32 & 40 & 24 & 24 & 24 & 20 & 16 & 12 & 12 & 420 \\
\hline & $\mathrm{Pc}=$ Percentil & & \multicolumn{6}{|c|}{$\begin{array}{l}\mathrm{LP}=\text { Logros profesionales } \\
\mathrm{L}=\text { Liderazgo } \\
\mathrm{HI}=\text { Habilidades de investigación } \\
\mathrm{RA}=\text { Responsabilidad académica } \\
\mathrm{CA}=\text { Concentración comprensión } \\
\mathrm{C}=\text { Creatividad e innovación } \\
\mathrm{SC}=\text { Socialización y compañerismo } \\
\mathrm{EG}=\text { Exposición frente a grupo }\end{array}$} & & & \multicolumn{5}{|c|}{$\begin{array}{l}\mathrm{OA}=\text { Organización académica } \\
\mathrm{Cl}=\text { Control de impulsos } \\
\mathrm{PA}=\text { Planeación académica } \\
\mathrm{AF}=\text { Aprendizaje fluido } \\
\mathrm{TP}=\text { Trabajo bajo presión } \\
\mathrm{Al}=\text { Asimilación de información } \\
\mathrm{ToV}=\text { Total de EAVA } \\
\mathrm{ToC}=\text { Total de EACA }\end{array}$} & \\
\hline
\end{tabular}

Nota: Elaboración con datos propios. 


\section{Discusión}

La presente investigación tuvo como propósito el desarrollo de un instrumento de medición que permitiese explorar el grado de autoeficacia en la vida académica de estudiantes de nuevo ingreso a la educación superior, como punto de partida para la acción tutorial. Contar con una visión clara y objetiva de las limitaciones adaptativas del alumnado al nuevo contexto universitario, mediante el empleo de medidas útiles y pertinentes que den cuenta de ello, es un recurso que contribuye al éxito de la acción tutorial y a la correcta formulación de sus objetivos inmediatos y específicos.

Así, a diferencia de otros estudios que han partido de la teoría para la determinación de reactivos (Galleguillos-Herrera y Olmedo-Moreno, 2019) o del juicio experto (Blanco Vega, et al., 2011), y a fin de contar con un instrumento derivado directamente del alumnado, la EAVA fue producto de la instrumentación de la técnica de frases incompletas a una muestra universitaria de estudiantes noveles; el resultado fue una escala multifactorial que ha mostrado adecuadas propiedades psicométricas en cuanto a validez estructural, confiabilidad y validez concurrente, si bien algunos de sus factores han presentado porcentajes conservadores de varianza explicada a cambio de un amplio espectro de dominios que permiten la identificación de autopercepciones en el alumnado, en relación con sus diferentes capacidades, que pueden o no dar cuenta de problemas adaptativos susceptibles de ser tratados por la acción tutorial. Este último punto habría de ser valorado psicológicamente en una entrevista posterior a la evaluación con la EAVA.

Como se ha descrito arriba, la autoeficacia es una variable que media la relación entre la personalidad de un sujeto y su comportamiento; ¿qué relación tiene la EAVA con los rasgos psicopatológicos y el malestar psicológico? De acuerdo con la bibliografía sobre el tema (Caprara et al., 2010; Caprara et al., 2011; Fosse et al., 2015; Gómez et al.2007;Tahmassian y Jalali-Moghadam, 2011), a partir de una muestra de 251 estudiantes de nuevo ingreso a la universidad, GarcíaMéndez y Rivera-Ledesma (2020a) exploraron la relación entre la EAVA y rasgos psicopatológicos evaluados mediante el empleo del Inventario multifásico de la personalidad de Minessota (MMPI-II) (Lucio et al., 1994). Encontraron que las áreas de introversión social, depresión, histeria, desviaciones psicopáticas, obsesivo-compulsivo (psicastenia) y esquizofrenia presentaban diferencias significativas entre sujetos normales y sujetos con psicopatología en diferentes factores de la EAVA. En otra investigación, García-Méndez y Rivera-Ledesma (2020b) indagaron el malestar psicológico en relación con la EAVA en dos grupos de sujetos, con malestar significativo y sin este, mediante el Listado de síntomas SCL90-R (Derogatis, 1975, 1994). La investigación aportó evidencia acerca de la relación entre medidas de desajuste psicológico centradas en el distrés y la autoeficacia en la vida académica. En ambas investigaciones fue evidente que, para algunas categorías correspondientes a niveles bajos de rasgos psicopatológicos, por un lado, o de distrés psicológico, por otro, correspondían mayores niveles de autoeficacia en la vida académica; y otras con alto distrés psicológico o mayores niveles de severidad en rasgos psicopatológicos, 
http://doi.org/10.15359/ree.25-2.1

http://www.una.ac.cr/educare

educare@una.ac.cr

ostentaban menores niveles de autoeficacia. Así, la EAVA, y en general la estimación de las creencias de autoeficacia académica, pueden dar indicios de la posible presencia de alteraciones emocionales de diverso grado de severidad que, en conjunto, podrían entorpecer la capacidad adaptativa o el adecuado desarrollo académico del estudiantado.

La Tabla 6 muestra la relación entre las áreas que conforman la EAVA, su definición y las posibles alternativas de acción tutorial para cada una con base en un enfoque cognitivoconductual, o mediante estrategias de intervención didáctico-instruccional. Como es sabido, el enfoque cognitivo-conductual es una alternativa importante de tratamiento psicológico en casos de personas con psicopatología significativa de diverso tipo, caracterizándose por operar en acuerdo con procedimientos constantemente evaluados en términos de su eficacia terapéutica. Es claro que los centros educativos no tienen por objetivo la atención psicoterapéutica de estudiantes con psicopatología significativa; sin embargo, se han realizado aproximaciones cognitivo conductuales exitosas (Haro-Soler, 2017; Villarroel Zuazua y González Ramírez, 2015) en sujetos universitarios. En otro contexto, Gil-Monte (2014) sugirió que, en un medio como el laboral, se busca facilitar el rendimiento, el aprendizaje y el desarrollo, en una labor de acompañamiento en la que el entrenamiento mediante un enfoque cognitivo conductual puede optimizar las habilidades, competencias y destrezas de una persona, en teoría funcional y con bajo nivel de psicopatología; objetivos similares a los buscados por la acción tutorial en educación. Haro-Soler (2017) ha desarrollado y descrito una intervención de corte cognitivo-conductual para el desarrollo de la autoeficacia, cuyos resultados muestran la importante articulación de este enfoque con la acción tutorial.

Tabla 6: Áreas de la EAVA y acción tutorial

Logros profesionales. Creencias de incapacidad para alcanzar logros y metas personales.

- Enfoque cognitivo-conductual para la superación de la baja autoestima, basado en las aportaciones de Fennell (1998), Kolubinski (2018).

- Terapia cognitiva (Ibáñez-Tarín y Manzanera-Escartí, 2014).

Liderazgo. Creencias de incapacidad para influir, dirigir, decidir, capacitar y planear en grupos. Liderazgo es una variable compuesta de otras como habilidades sociales, asertividad, manejo de estrés, solución de problemas y empatia.

- Entrenamiento en habilidades sociales (Caballo, 2007).

- Entrenamiento en asertividad y habilidades sociales (García Grau et al., 2019).

- Inoculación de estrés (Ibáñez-Tarín y Manzanera-Escartí, 2012).

- Entrenamiento en solución de problemas (Bados y García, 2014).

- Concientización en características del liderazgo mediante restructuración cognitiva (United Nations Educational, Scientific and Cultural Organization [UNESCO], 2012). 
http://doi.org/10.15359/ree.25-2.1

Habilidades de investigación. Creencias de incapacidad para aplicar el sentido común en la identificación básica de procedimientos apropiados para resolver problemas que requieren investigación. Desconocimiento de fuentes de información válidas y confiables y su manejo. Capacidad de redacción con ortografía adecuada.

- Generación de actitudes investigativas favorables (Acosta Muñoz, 2013).

- Describir cómo es; comparar entre un antes de y un después de; entre ser así, y no ser así; entre anteayer, ayer y hoy; predecir cómo será.

- ¿Dónde está la información y qué hacer con ella?

Responsabilidad académica. Creencias de incapacidad para identificarse con los objetivos y metas académicas y asumirlos como objetivos y metas propios.

- Educar la responsabilidad profesional (González Maura et al., 2007).

- Determinación del sentido: Por qué, para qué y para quién estoy yo aquí?

- Responsabilidad: Mi respuesta a algo que siento que me concierne.

Concentración y comprensión académicas. Creencias de incapacidad para concentrarse en lecturas y el estudio.

- Desarrollo del hábito de la lectura/Biblioterapia (Ibáñez-Tarín y Manzanera-Escartí, 2012).

- Estrategias para comprensión lectora (Guerra Morales y Forero Baena, 2015).

- Potenciar la atención / Concentración (Caamaño Silva, 2018).

- Determinación del sentido: Por qué, para qué y para quién, estoy yo aquí?

Creatividad e innovación. Creencias de incapacidad para reaccionar con ideas y soluciones creativas e innovadoras ante problemas dados.

- Entrenamiento en creatividad e innovación (Organización de las Naciones Unidas para el Desarrollo Industrial [ONUDI], 2020.)

Socialización y compañerismo. Creencias de incapacidad para interactuar con las demás personas de manera espontánea, participativa, colaborativa y empática, sin experimentar ansiedad, sentimientos de inadecuación o rechazo social.

- Entrenamiento en habilidades sociales (Caballo, 2007).

- Entrenamiento en solución de problemas (Bados y García, 2014).

- Terapia cognitiva (Ibañez-Tarin y Manzanera-Escartí, 2014).

Exposición frente a grupo. Creencias de incapacidad para afrontar o dirigirse a un grupo durante la exposición de argumentos propios de manera sostenida.

- Enfoque cognitivo-conductual utilizando los métodos de exposición, entrenamiento en relajación, entrenamiento en habilidades sociales y reestructuración cognitiva mediante terapia racional emotiva (Caballo et al., 2007).

Organización y planeación académicas. Creencias de incapacidad para organizar y planear sus propias actividades académicas (tiempo, tareas, exposiciones, etc.).

• Hábitos de estudio: planificación y organización del tiempo (Universidad de Granada (s.f.). 
http://doi.org/10.15359/ree.25-2.1

http://www.una.ac.cr/educare

educare@una.ac.cr

Control de impulsos. Creencias de incapacidad para controlar impulsos agresivos bajo situaciones estresantes; baja tolerancia a la demanda de demora.

- Entrenamiento en estrategias de afrontamiento y manejo del estrés. El afrontamiento del estrés: Estrategias cognitivo-conductuales (Rice, 1998).

- Habilidades de afrontamiento cognitivas / de relajación (HACR) para el control de la ira. Intervención cognitivoconductual para el control de la ira (Deffenbacher y Lynch, 1998).

Aprendizaje fluido. Creencias de incapacidad para aprender información de manera inmediata.

- Aprender a aprender (Guido Williamson, 2012).

Trabajo bajo presión. Baja capacidad para trabajar eficientemente en condiciones de estrés.

- Entrenamiento en estrategias de afrontamiento y manejo del estrés. El afrontamiento del estrés: Estrategias cognitivo-conductuales (Rice, 1998).

- Inoculación de estrés (Ibáñez-Tarín y Manzanera-Escartí, 2012).

Asimilación de información. Creencias de incapacidad para aprender de manera dinámica en trabajo grupal.

- ¿Qué es el aprendizaje? (Fairstein y Gyssels, 2003).

Nota: Elaboración propia.

A partir de lo revisado arriba, es importante considerar, en futuras investigaciones, la realización de estudios tendientes a evaluar la sensibilidad y especificidad de la EAVA (Pita Fernández y Pértegas Díaz, 2003), en la identificación de casos y no casos de alumnado en riesgo; alumnado novel con problemas adaptativos, ansiosos o depresivos, producto de la transición académica a la que está sometido, o con carencias de autoestima, habilidades sociales, etc., que le haga vulnerable al fracaso o la deserción universitaria. Adicionalmente, es importante considerar que el empleo de la EAVA debería ser llevado a cabo en conjunción con instrumentos clínicos como el Listado de síntomas SCL90-R que permitan obtener una visión multifactorial válida y confiable acerca del estado emocional del estudiantado, a fin de complementar los resultados en autoeficacia en la vida académica.

Debe tenerse presente que las creencias de autoeficacia académica pueden verse notoriamente influidas por aspectos sociales y culturales de la zona, región o institución educativa en que estas sean evaluadas. La EAVA fue desarrollada con base en muestras de la Ciudad de México y el Estado de Morelos y en estudiantes de nuevo ingreso a la universidad, lo cual debe alertar a futuras investigaciones con respecto a evaluar su pertinencia en distintas zonas y niveles educativos.

Por otro lado, la extensión de la EAVA (102 reactivos), puede ser un inconveniente en la realización de investigaciones enfocadas a un amplio número de variables; instrumentos como la Escala de autoeficacia en conductas académicas (Blanco Vega et al., 2011) y la Escala de autoeficacia académica (Galleguillos-Herrera y Olmedo-Moreno, 2019) podrían ser mejor opción por sus características robustas y un menor número de reactivos. 
La presente investigación ha propuesto el empleo de instrumentos de medición (EAVA, SCL90-R), que permitirían arribar a un diagnóstico fundamentado acerca de la condición adaptativa del alumnado, de tal suerte que tales resultados sean, metodológicamente, congruentes con métodos y técnicas de intervención psicológica y educativa con efectos en el corto plazo y resultados medibles. El resultado de esta postura centrada en el entrenamiento de competencias para el fortalecimiento de la capacidad adaptativa del estudiantado permite enriquecer, en alguna medida, el objetivo fundamental de todo centro educativo: Educar para la vida.

\section{Declaración de Material complementario}

Este artículo tiene disponible, como material complementario:

-La versión preprint del artículo en https://doi.org/10.5281/zenodo.3661265

\section{Referencias}

Acosta Muñoz, J. F. (2013). Las actitudes investigativas en la formación escolar. Praxis \& Saber, 4(8), 109-133. https://doi.org/10.19053/22160159.2654

Alina Karouei, R., Borjali, A., Jomehri, F. y Sohrabi, F. (2008). Relationship between general selfefficacy and psychopathological symptoms in high school students, Journal of Psychology, 12(2), 122-135 https://www.sid.ir/en/journal/ViewPaper.aspx?id=152445

Álvarez, D.A. y Pons, F.E. (2013). Educar para transformar. Universidad Europea Madrid.

Babío Galán, M. (2011). Orientación y transición entre etapas. En E. Martín e I. Solé (Coords.), Orientación educativa: Modelos y estrategias de intervención (pp. 151-167). Graó. https:// dialnet.unirioja.es/servlet/libro?codigo $=466791$

Bados, A. y García Grau, E. (2014). Resolución de problemas. Universidad de Barcelona. Facultat de Psicologia Departament de Personalitat, Avaluació i Tractament Psicològics. http://diposit. ub.edu/dspace/bitstream/2445/54764/1/Resoluci\%C3\%B3n\%20problemas.pdf

Bandura, A. (1977). Self-efficacy: Toward a unifying theory of behavior change. Psychological Review, 84(2), 191-215. https://doi.org/10.1037/0033-295X.84.2.191

Bandura, A. (1982). Self-efficacy mechanism in human agency. American Psichologist, 37(2), $122-$ 147. https://doi.org/10.1037/0003-066X.37.2.122

Bandura, A. (1995). 1. Exercise of personal and collective efficacy in changing societies. En A. Bandura (Ed.), Self-efficacy in changing societies (pp. 1-45). Cambridge University Press. https://www.researchgate.net/profile/Barry_Zimmerman/publication/247480203 Selfefficacy and educational development/links/549b67770cf2b80371371ad5/Selfefficacy-and-educational-development.pdf 
http://doi.org/10.15359/ree.25-2.1

http://www.una.ac.cr/educare

educare@una.ac.cr

Barraza Macías, A. (2010). Validación del inventario de expectativas de autoeficacia académica en tres muestras secuenciales e independientes. CPU-e, Revista de Investigación Educativa, 10, 1-30. https://www.uv.mx/cpue/num10/inves/completos/barraza validacion.pdf

Bereziartua, J., Zubiri, A., Intxausti, N.y Odriozola, A. (2017). Acción tutorial en la transición del alumnado de las escuelas del medio rural a la educación secundaria. Tendencias Pedagógicas, 29, 189-210. https://doi.org/10.15366/tp2017.29.008

Blanco Vega, H., Martínez Marín, M., Zueck Enríquez, M. del C. y Gastélum Cuadras, G. (2011). Análisis psicométrico de la escala Autoeficacia en conductas académicas en universitarios de primer ingreso. Actualidades Investigativas en Educación, 11(3), 1-27. https://doi. org/10.15517/aie.v11i3.10214

Borzone Valdebenito, M. A. (2017). Autoeficacia y vivencias académicas en estudiantes universitarios. Acta Colombiana de Psicología, 20(1), 266-274. https://doi.org/10.14718/ ACP.2017.20.1.13

Burris, J. L., Brechting, E. H., Salsman, J. y Carlson, C. R. (2009). Factors associated with the psychological well-being and distress of university students. Journal of American College Health, 57(5), 536-544. https://doi.org/10.3200/JACH.57.5.536-544

Caamaño Silva, C. (2018). Claves para potenciar la atención/concentración. Guía de orientación para universitarios. Universidad de Chile.

Caballo, V. E. (2007). Manual de evaluación y entrenamiento de las habilidades sociales (7. ${ }^{\mathrm{a}} \mathrm{ed}$.). Siglo XXI. https://cideps.com/wp-content/uploads/2015/04/Caballo-V.-Manual-deevaluaci\%C3\%B3n-y-entrenamiento-de-las-habilidades-sociales-ebook.pdf

Caballo, V. E., Andrés, V. y Bas, F. (2007). 2. Fobia social. En V. E. Caballo (Dir), Manual para el tratamiento cognitivo-conductual de los trastornos psicológicos (Vol. 1. Trastornos por ansiedad, sexuales, afectivos y psicóticos, pp. 25-87). Siglo XXI. https://www.academia. edu/20393082/Caballo_2007_manual_para_el_tratamiento_cognitivo_conductual_de los trastornos

Caprara, G. V., Alessandri, G., Di Giunta, L., Panerai, L. y Eisenberg, N. (2010). The contribution of agreeableness and self-efficacy beliefs to prosociality. European Journal of Personality, 24(1), 36-55. https://doi.org/10.1002/per.739

Caprara, G. V., Vecchione, M., Alessandri, G., Gerbino, M. y Barbaranelli, C. (2011). The contribution of personality traits and self-efficacy beliefs to academic achievement: A longitudinal study. British Journal of Educational Psychology, 81(1), 78-96. https://doi.org/10.1348/2044-8279.002004 
http://doi.org/10.15359/ree.25-2.1

de la Cruz Flores, G., Chehaybar Kury, E. y Abreu, L. F. (2011). Tutoría en educación superior: Una revisión analítica de la literatura. Revista de la Educación Superior, 40(157), 189-209. http:// www.scielo.org.mx/pdf/resu/v40n157/v40n157a9.pdf

Deffenbacher, J. L. y Lynch, R.S. (1998). 20. Intervención cognitivo-conductual para el control de la ira. En V. E. Caballo (Dir), Manual para el tratamiento cognitivo-conductual de los trastornos psicológicos (Vol. 2. Formulación clínica, medicina conductual y trastornos de relación, pp. 639-674). Siglo XXI. https://cideps.com/wp-content/uploads/2015/04/CaballoV.-Manual-para-el-tratamientocognitivo-conductual-de-los-trastornos-psicol\%C3\%B3gicos-Vol.2-ebook.pdf

Derogatis, L. R. (1975). The SCL-90-R. Clinical Psychometric Research.

Derogatis, L. R. (1994). SCL-90-R. Administration, scoring and procedures manual (3. a ed.). National Computer Systems.

Dominguez-Lara, S. A. (2016). Valores normativos de una escala de autoeficacia académica en estudiantes universitarios de Lima.Interacciones, 2(2), 91-98.https://doi.org/10.24016/2016. v2n2.31

Fairstein, G. A. y Gyssels, S. (2003). ¿Cómo se aprende? Federación Internacional de Fe y Alegría. https://www.redec.es/sites/default/files/como se aprende.pdf

Fennell,M.J.V.(1998).Cognitivetherapyinthetreatmentoflowself-esteem.Advancesin Psychiatric Treatment, 4, 296-304. https://www.cambridge.org/core/services/aop-cambridge-core/ content/view/2E1AD8A59C47DE34887432D53D4C6B2A/S1355514600015893a.pdf/ cognitive therapy in the treatment of low selfesteem.pdf

Fosse, T. H., Buch, R., Säfvenbom, R. y Martinussen, M. (2015). The impact of personality and self-efficacy on academic and military performance: The mediating role of self-efficacy. Journal of Military Studies, 6(1), 1-19. https://doi.org/10.1515/jms-2016-0197

Galleguillos-Herrera, P. y Olmedo-Moreno, E. (2019). Autoeficacia y motivación académica: Una medición para el logro de objetivos escolares. European Journal of Investigation in Health, Psychology and Education, 9(3), 119-135. https://formacionasunivep.com/ejihpe/index. php/journal/article/view/329/199

García Grau, E., Fusté Escolano, A., Ruiz Rodríguez, J., Arcos Pros, M., Balaguer Fort, G., Guzmán Pérez, D. y Bados López, A. (2019). Entrenamiento en asertividad y habilidades sociales. Universidad de Barcelona. http://diposit.ub.edu/dspace/bitstream/2445/136063/1/ ENTRENAMIENTO\%20EN\%20ASERTIVIDAD\%20Y\%20HABILIDADES\%20SOCIALES.pdf

García-Méndez, R. M. y Rivera-Ledesma, A. (2020a). Autoeficacia en la vida académica y rasgos psicopatológicos. Revista Argentina de Ciencias del Comportamiento, 12(3), 41-58. https:// doi.org/10.32348/1852.4206.v12.n3 
http://doi.org/10.15359/ree.25-2.1

http://www.una.ac.cr/educare

educare@una.ac.cr

García-Méndez, R. M. y Rivera-Ledesma, A. (2020b). Escala de autoeficacia en la vida académica y distrés psicológico [En revisión].

Gempp, R. y Saíz, J. L. (2014). El coeficiente $K^{2}$ de Livinston y la fiabilidad de una decisión dicotómica en un test psicológico. Universitas Psychologica, 13(1), 217-226. https://doi. org/10.11144/Javeriana.UPSY13-1.eckl

Gil-Monte, P. R. (2014). Coaching cognitivo conductual: Una herramienta para los psicólogos. Información Psicológica, 107, 34-46. http://www.informaciopsicologica.info/OJSmottif/ index.php/leonardo/article/view/204

Gómez, V., Villegas de Posada, C., Barrera, F., Cruz, J. E. (2007). Factores predictores de bienestar subjetivo en una muestra colombiana. Revista Latinoamericana de Psicología, 39(2), 311325. https://www.redalyc.org/pdf/805/80539208.pdf

González Cabanach, R., Valle Arias, A., Freire Rodríguez, C.y Ferradás Canedo, M. (2012). Relaciones entre la autoeficacia percibida y el bienestar psicológico en estudiantes universitarios. Revista Mexicana de Psicología, 29(1), 40-48. https://www.academia.edu/5828344/ Relaciones entre_la_autoeficacia_percibida_y_el_bienestar_psicol\%C3\%B3gico_en estudiantes universitarios

González Maura, V., Blández Ángel, J., Sierra Zamorano, M. Á. y López Rodríguez, A. (2007). Educar la responsabilidad profesional a través de la investigación-acción. Una experiencia en la formación del profesorado en Educación Física. Tiempo de Educar, 8(15), 113-138. https://www.redalyc.org/pdf/311/31181505.pdf

GuerraMorales, E.yForeroBaena,C.(2015).Estrategias paraeldesarrollodelacomprensióndetextos académicos. Zona Próxima, 22, 33-55. https://www.redalyc.org/pdf/853/85339658004.pdf

Guido Williamson, L. (2012). Aprender a aprender. Red Tercer Milenio. http://www.aliat.org.mx/ BibliotecasDigitales/Educacion/Aprender a aprender.pdf

Haro Soler, M. del M. (2017). ¿Cómo desarrollar la autoeficacia del estudiantado? Presentación y evaluación de una experiencia formativa en el aula de traducción. Revista Digital de Investigaciónen DocenciaUniversitaria, 11(2),50-74. http://dx.doi.org/10.19083/ridu.11.567

Ibáñez-Tarín, C. y Manzanera-Escartí, R. (2012). Técnicas cognitivo-conductuales de fácil aplicación en atención primaria (I). Semergen, 38(6), 377-387. https://www.elsevier.es/esrevista-medicina-familia-semergen-40-pdf-S113835931200069X

Ibáñez-Tarín, C. y Manzanera-Escartí, R. (2014).Técnicas cognitivo-conductuales de fácil aplicación en atención primaria (Parte 2). Semergen, 40(1), 34-41. https://pdfslide.net/documents/ tecnicas-cognitivo-conductuales-de-facil-aplicacion-en-asistencia-primaria.html 
http://doi.org/10.15359/ree.25-2.1

Kohler Herrera, J. (2009). Rendimiento académico asociado a la autoeficacia de estudiantes de 4to. y 5to. año de secundaria de un colegio nacional de Lima. Cultura, 23, 101-119. http:// www.revistacultura.com.pe/imagenes/pdf/23 18.pdf

Kolubinski, D. C., Frings, D., Nikčević, A. V., Lawrencea, J. A. y Spada, M. M. (2018). A systematic review and meta-analysis of CBT interventions based on the Fennell model of low self-esteem Psychiatry Research, 267, 296-305. https://www.researchgate. net/publication/325681747 A Systematic Review and Meta-Analysis of CBT Interventions Based on the Fennell Model_of_Low Self-Esteem

López Martín, I., Blanco Fernández, A., Pagán Marín, R. M., Gazapo Andrade, B., de Arana del Valle, J. M., Pizarro Juanas, E. A. y Martínez Pascual, B. (2014). Estudio cualitativo sobre tutoría universitaria a través del método de panel de expertos. Higher Learning Research Communications, 4(1), 73-90. http://dx.doi.org/10.18870/h/rc.v4i1.197

Lucio, E., Reyes-Lagunes, I. y Scott, R. L. (1994). MMPI-2 for México: Translation and adaptation. Journal of Personality Assessment, 63(1), 105-116. https://doi.org/10.1207/ s15327752jpa6301 9

Maglio, N., Fatelevich, M., Luque, A. E., Biasella, R. y Melillo, O. (2010). Frases incompletas de J. Sacks y S. Levy: Relación materna. II Congreso Internacional de Investigación y Práctica Profesional en Psicología. XVII Jornadas de Investigación. Sexto Encuentro de Investigadores en Psicología del MERCOSUR. https://www.aacademica.org/000-031/935.pdf

Martínez Licona, J. F., Torres Padilla, M. Á. y Huerta Mata, R. M. (2005). Los planes de acción tutorial en la UASLP. La trayectoria académica como eje de construcción. REMO. Revista Mexicana de Orientación Educativa, 3(5), 34-37. http://remo.ws/remo-5/

Morales Vallejo, P. (2012). El tamaño del efecto (effect size): Análisis complementarios al contraste de medias. Universidad Pontificia Comillas. http://web.upcomillas.es/personal/peter/ investigacion/Tama\%C3\%B1oDelEfecto.pdf

Muris, P. (2002). Relationships between self-efficacy and symptoms of anxiety disorders and depression in a normal adolescent sample. Personality and Individual Differences, 32(2), 337-348. https://www.sciencedirect.com/science/article/abs/pii/S0191886901000277

Organización de las Naciones Unidas para el Desarrollo Industrial. (2020). Innovación y creatividad en la búsqueda de opciones, análisis de viabilidad, fuentes de información. Autor. https:// www.unido.org/sites/default/files/2008-06/5-Textbook 0.pdf

Pita Fernández, S. y Pértegas Díaz, S. (2003). Pruebas diagnósticas: Sensibilidad y especificidad. Cadernos de Atención Primaria, 10, 120-124. https://www.fisterra.com/mbe/investiga/ pruebas diagnosticas/pruebas diagnosticas.asp 
http://doi.org/10.15359/ree.25-2.1

http://www.una.ac.cr/educare

educare@una.ac.cr

Rice, P. L. (1998). 9. El afrontamiento del estrés: Estrategias cognitivo-conductuales. En V. E. Caballo (Dir), Manual para el tratamiento cognitivo-conductual de los trastornos psicológicos. Vol. 2. Formulación clínica, medicina conductual y trastornos de relación (pp. 323-358). Siglo XXI. https://cideps.com/wp-content/uploads/2015/04/CaballoV.-Manual-para-el-tratamientocognitivo-conductual-de-los-trastornos-psicol\%C3\%B3gicos-Vol.2-ebook.pdf

Sabogal, L. F. (2004). Pruebas proyectivas: Acerca de su validez y confiabilidad. Duazary, 1(2), 134-137. doi.org/10.21676/2389783X.595

Sanjuán Suárez, P., Pérez García, A. M. y Bermúdez Moreno, J. (2000). Escala de autoeficacia general: Datos psicométricos de la adaptación para población española. Psicothema, 12(2), 509-513. http://www.psicothema.com/pdf/615.pdf

Sneiderman, S. (2006). Las técnicas proyectivas como método de investigación y diagnóstico. Actualización en técnicas verbales: El cuestionario desiderativo. Subjetividad y Procesos Cognitivos, 8, 296-331. https://www.redalyc.org/pdf/3396/339630247014.pdf

Tahmassian, K. y Jalali-Moghadam, N. J. (2011). Relationship between self-efficacy and symptoms of anxiety, depression, worry and social avoidance in a normal sample of students. Iranian Journal of Psychiatry and Behavioral Sciences, 5(2), 91-98. https://www.ncbi.nlm.nih.gov/ pmc/articles/PMC3939966/

Tejada Zabaleta, A. (2005). Agenciación humana en la teoría cognitivo social: Definición y posibilidades de aplicación. Pensamiento Psicológico, 1(5), 117-123. https://dialnet.unirioja. es/descarga/articulo/4800697.pdf

United Nations Educational, Scientific and Cultural Organization. (2012). Fácil guía 2. Liderazgo y organización. UNESDOC Biblioteca digital. https://unesdoc.unesco.org/ark:/48223/ pf0000228344

Universidad de Granada (s.f.). Hábitos de estudio: Planificación y organización del tiempo. Universidad de Granada. Vicerrectorado de Estudiantes y Empleabilidad. https:// ve.ugr.es/sites/vicerrectorados files/vic ve/public/ficheros/extendidas/2018-12/ Ha\%CC\%81bitos\%20de\%20Estudio.pdf

Villarroel Zuazua, A. L. y González Ramírez, M. T. (2015). Intervención cognitivo-conductual y centrada en soluciones para disminuir el estrés académico en estudiantes universitarios. Revista Electrónica de Psicología Iztacala, 18(4), 1363-1387. https://www.medigraphic.com/ pdfs/epsicologia/epi-2015/epi154d.pdf 
http://doi.org/10.15359/ree.25-2.1

http://www.una.ac.cr/educare educare@una.ac.cr

Apéndice A: Escala de autoeficacia en vida académica

\begin{aligned} & \hline No. \\ & \hline 1 Alcanzar mis metas. \\ & \hline 2 Organizar a un grupo de personas para realizar actividades. \\ & \hline 3 Elaborar investigaciones. \\ & \hline 4 Ser puntual. \\ & \hline 5 Concentrarme cuando leo. \\ & \hline 6 Ser innovador(a). \\ & \hline 7 Ser sociable. \\ & \hline 8 Exponer. \\ & \hline 9 Ser una persona organizada. \\ & \hline 10 Controlar mis impulsos. \\ & \hline 11 Planear con tiempo las actividades académicas. \\ & \hline 12 Aprender rápido. \\ & \hline 13 Trabajar con poco tiempo para terminar. \\ & \hline 14 Aprender más rápido con ejemplos de los temas. \\ & \hline 15 Lograr todo lo que me proponga. \\ & \hline 16 Capacitar a las personas. \\ & \hline 17 Indagar más sobre diferentes temas vistos en clase. \\ & \hline 18 Llegar temprano a clases. \\ & \hline 19 Concentrarme en un tema por mucho tiempo. \\ & \hline 20 Tener buenas ideas. \\ & \hline 21 Convivir con las personas sin ningún problema. \\ & \hline 22 Exponer algún tema en clase. \\ & \hline 23 Ser ordenada(o). \\ & \hline 24 Controlarme cuando me estreso con facilidad. \\ & \hline 25 Cumplir rápido mis metas universitarias. \\ & \hline 26 Aprender rápido los temas vistos en clase. \\ & \hline 27 Trabajar bajo presión. \\ & \hline 28 Adquirir nuevos conocimientos. \\ & \hline 30 Aportar conocimiento a un grupo grande de personas. \\ & \hline\end{aligned}

continúa 
http://doi.org/10.15359/ree.25-2.1

http://www.una.ac.cr/educare

educare@una.ac.cr

\begin{aligned} & \hline No. \multicolumn{1}{c}{ Ítems } \\ & \hline 31 Redactar. \\ & \hline 32 Levantarme temprano para asistir a clases. \\ & \hline 33 Memorizar términos y conceptos. \\ & \hline 34 Comprender los temas vistos en clase. \\ & \hline 35 Realizar varias actividades al mismo tiempo. \\ & \hline 36 Aprender con facilidad los temas vistos en clase. \\ & \hline 37 Crear planes de trabajo. \\ & \hline 38 Controlar mi ira en clase. \\ & \hline 39 Hablar frente a mis profesores. \\ & \hline 40 Tener una buena comunicación con mis compañeros(as). \\ & \hline 41 Ser creativo(a). \\ & \hline 42 Terminar mi carrera. \\ & \hline 43 Influir en las personas con mis ideas. \\ & \hline 44 Realizar correctamente trabajos escritos. \\ & \hline 45 Comprometerme. \\ & \hline 46 Comprender a fondo a los autores(as). \\ & \hline 47 Poder aportar cosas nuevas. \\ & \hline 48 Hablar frente a mis compañeros(as). \\ & \hline 49 Poder mantener una amistad duradera. \\ & \hline 50 Realizar con tiempo mis actividades académicas. \\ & \hline 51 Ser una persona paciente. \\ & \hline 52 Poder administrar mi tiempo libre. \\ & \hline 53 Poner atención en clase. \\ & \hline 54 Comprender lecturas asignadas en clase. \\ & \hline 55 Cumplir con investigaciones y tareas a entregar. \\ & \hline 56 Analizar textos vistos en clase sin ayuda de maestros. \\ & \hline 57 Dirigir grupos grandes de personas. \\ & \hline 58 Interactuar con las demás personas. \\ & \hline 60 Apoyar a mis compañeros(as) cuando lo necesitan. \\ & \hline\end{aligned}

continúa 
http://doi.org/10.15359/ree.25-2.1

\begin{aligned} & \hline No. \\ & \hline 62 Planear las exposiciones. \\ & \hline 63 Leer sin distraerme. \\ & \hline 64 Ser responsable. \\ & \hline 65 Investigar temas que requieren de mucho tiempo de estudio. \\ & \hline 66 Tomar decisiones para beneficio de mis compañeros(as). \\ & \hline 67 Buscar más información cuando la necesito. \\ & \hline 68 Acudir todos los días a la escuela. \\ & \hline 69 Concentrarme bien para redactar algún trabajo. \\ & \hline 70 Ser emocionalmente estable. \\ & \hline 71 Organizar mi tiempo. \\ & \hline 72 Solucionar problemas académicos. \\ & \hline 73 Expresar mis ideas frente al grupo. \\ & \hline 74 Trabajar en equipo. \\ & \hline 75 Ser líder. \\ & \hline 76 Llevar a cabo la planeación de un evento. \\ & \hline 77 Resolver tareas de investigación. \\ & \hline 78 Ser puntual para entregar trabajos. \\ & \hline 79 Poner en práctica correctamente lo aprendido. \\ & \hline 80 Concentrarme en estudiar para los exámenes. \\ & \hline 81 Ser meticuloso(a) cuando hay que analizar información. \\ & \hline 82 Hacer tareas. \\ & \hline 83 Tomar mis propias decisiones. \\ & \hline 84 Terminar la carrera con honores. \\ & \hline 85 Ser emprendedor(a). \\ & \hline 86 Acercarme a un desconocido(a) y entablar una conversación con él/ella. \\ & \hline 87 Organizar mis actividades dentro de la escuela. \\ & \hline 88 Elaborar gráficas que sirvan de apoyo. \\ & \hline 89 Explicar al que no comprende. \\ & \hline 91 Investigar temas por mi cuenta. \\ & \hline\end{aligned}

continúa 
http://doi.org/10.15359/ree.25-2.1

http://www.una.ac.cr/educare

educare@una.ac.cr

\begin{aligned} & \hline No. \multicolumn{1}{c}{ Ítems } \\ & \hline 93 Sacar buenas calificaciones. \\ & \hline 94 Poder improvisar. \\ & \hline 95 Poder realizar actividades con personas que no conozco. \\ & \hline 96 Apreciar el arte. \\ & \hline 97 Ser una persona constante. \\ & \hline 98 Ser considerado(a) con las demás personas. \\ & \hline 99 Ser competente. \\ & \hline 100 Obtener un trabajo relacionado con mi carrera. \\ & \hline 101 Sobresalir ante cualquier situación. \\ & \hline 102 Aprender inglés. \\ & \hline\end{aligned}

Opciones de respuesta: 1 . Nunca o casi nunca; 2 . Algunas veces; 3 . Frecuentemente y 4. Siempre o casi siempre.

Nota: Elaboración con datos propios. 